\title{
Control-oriented modelling and analysis of a solid oxide fuel cell system $^{\star}$
}

\author{
Yashan Xing $^{a}$, Ramon Costa-Castellóo,*, Jing $\mathrm{Na}^{b}$ and Hugues Renaudineau ${ }^{a}$ \\ ${ }^{a}$ Institut de Robòtica i Informàtica Industrial, CSIC-UPC. C/Llorens i Artigas 4-6, 08028 Barcelona, Spain \\ ${ }^{b}$ Faculty of Mechanical and Electrical Engineering, Kunming University of Science and Technology, Kunming, 650500, P.R. China
}

\section{ARTICLE INFO}

\section{Keywords:}

Control-oriented model

Solid Oxide Fuel cell

Parameter tuning

Stability analysis

\begin{abstract}
A B S TRACT
In this paper, a control-oriented model of a solid oxide fuel cell system is formulated and analyzed in detail. First, a lumped model based on first principle laws is formulated and tuned using experimental data coming from a real solid oxide fuel cell system test bench. The model calibration is carried out based on an optimization approach to minimize the error between the experimental data and the model one. To systematically analyze the system behavior, an equilibrium point analysis is formulated and developed. The analysis results show the maximum steady-state electrical power under each constant stack temperature. This will allow to appropriately select operation points during the system operation. Secondly, Lyapunov's theory is used to characterize the local stability of the equilibrium points. The results show that the equilibrium points are locally stable. Besides, comparison between the initial nonlinear model with the linearized model is performed to show the efficacy of the linearied model analysis. Finally, the frequency response of the linearized model is performed. This analysis provides key information about control system design in order to efficiently operate the solid oxide fuel cell system.
\end{abstract}

\section{Introduction}

Ever increasing global energy demands and rising public awareness for environmental protection have motivated to look for renewable energy sources. In recent year, hydrogen has been regarded as an attractive sustainable energy carrier. Fuel cells as hydrogen energy conversion devices draw considerable attentions due to various advantages, such as high efficiency, zero emission, and modularity. There are different types of fuel cells, such as polymer electrolyte membrane fuel cell (PEMFC), solid oxide fuel cell (SOFC) and alkaline fuel cell (AFC), etc. Fuel cell modeling is a challenging problem which is currently being addressed in the literature $[3,19]$.

Among fuel cells, SOFCs are one of those which are currently receiving more attention in research and development. They can operate at high temperature due to its solid electrolyte material, which leads to more flexible fuel selection and higher tolerance of impurities. However, the major obstacle of SOFCs for widely commercial utilization is their reduced lifetime due to degradation [14]. Hence, reliable modelling of SOFCs is required for interpreting

* This work was partially funded by ACCIÓ (Operational Program FEDER Catalunya 2014-2020) through the REFER project (COMRDI151-0036-11), the Spanish national project DOVELAR (ref. RTI2018096001-B-C32) and the Spanish State Research Agency through the María de Maeztu Seal of Excellence to IRI (MDM-2016-0656). This work was partially funded by AGAUR of Generalitat de Catalunya through the Advanced Control Systems (SAC) group grant (2017 SGR 482) and Chinese Scholarship Council (CSC) under grant (201808390007).

${ }^{*}$ Corresponding author

- yashan.xing@outlook.com (Y. Xing); ramon. costa@upc. edu (R. Costa-Castelló); najing25@163. com (J. Na); renaudineau. h@gmail. com (H. Renaudineau)

ORCID(s): $0000-0003-0358-012 x$ (Y. Xing); $0000-0003-2553-5901$ (R. Costa-Castelló); $0000-0002-3067-1580$ (J. Na); 0000-0002-3492-4979 (H. Renaudineau) and understanding their behavior and formulating operation mechanisms which allow to extend their lifetime.

During past decades, modelling SOFC has been carried out by extensive researchers [22]. In brief, SOFC models can be separated into three categories:

- Physical laws models. Different SOFC models have been proposed by using physical laws. They can be classified according to their dimensions, which vary from zero-dimensional (0-D) to three-dimensional (3D). Moreover, physical models are mainly concerned with inner electrochemical reaction, physical structure and material property. To be specific, the 0 -D model is also called lumped model which is appropriate for simulating transient and steady-state performances although physical size and distribution properties are not considered. In [12], a lumped model was proposed, where the electro-chemical reaction and thermal balance were considered. Moreover, 1-D and 3-D models mainly focus on the stack temperature distribution, gas flow direction and physical structure. In [18], an 1-D model was developed by dividing gas flows and voltage losses into small computational elements along the stream direction. In [21], a 3D fluid dynamics model was presented to illustrate concentration and pressure of gases and temperature distribution along gas channels and physical structure. The models from 1-D to 3-D are very convenient to analyze distributed properties, such as temperature gradients. This information is very important during the SOFC design, i.e. selecting appropriate structures and materials or placing sensors in representative points. Its complexity makes them not appropriate for control purposes.

- Semi-empirical models. These types of models 
are developed by combining physical laws and empirical data. Compared with mechanistic model, some variables in semi-empirical model are directly replaced by mathematical relation which depend on the prior knowledge of SOFC operation process. In [6], a kinetic formulation of polarization curve based on experiments was proposed to combine with a twodimensional model, which simulated gas temperature distribution and validated by experimental data.

- Empirical models. SOFC can be modelled directly through experimental data without using explicitly physical governing equations. In those models, artificial intelligent methods, such as artificial neural network [11], radial basis function neural network [23] and least squares support vector machine [8], are usually used. However, those models require a plenty of experimental data which introduce a long time for collecting experimental data and heavy computational costs.

Fuel cells have complex dynamics that are highly nonlinear and distributed, which make the developed models difficult to manage and apply in the control systems design. Despite this, there are plenty of control strategies and optimization methods that have been developed in order to maximize the system efficiency and maintain SOFC operation in safe conditions. In [2], gas flow rates and current were chosen as control inputs, and PID controllers were used to maintain stack temperature and achieve SOFC safe operation. In [25], a time delay control were designed to allow the load-following and avoid fuel starvation. However, the lack of information related to the stack temperature and electrical power with gas flows and current makes it difficult to maximize the system efficiency. More recently, an analysis was proposed to achieve the maximum efficiency using an artificial neural network model [5]. To the best of our knowledge, a systematic analysis for a SOFC system models with respect to efficiency and stability has not been addressed in the literature. Motivated by this fact, a methodology to analyze and dynamically characterize SOFC model is presented in this paper. Specifically, a controloriented model for a real SOFC system is proposed. Then, the model calibration and validation are presented adopting an optimization approach to minimize the discrepancies between the experimental data and the data generated by the model. In order to dynamically characterize the model behavior, the equilibrium points (i.e. the steadystate operation points) are obtained. This will be very helpful to understand under which conditions the SOFC can operate and which ones are the most convenient according to different requirements. The steady-state polarization curve obtained from equilibrium points represents the trade-off between electrical power and stack temperature. Besides, the proposed nonlinear model is linearized around equilibrium points in order to determine its local stability. The validity range of the linear models obtained around the equilibrium points is qualitatively analyzed by comparing the step response of the linear system and the nonlinear system. Finally, the frequency response of the linearized model is performed to show the coupled impacts between input and output variables.

The main contributions of this paper can be summarized as follows:

1) Formulation, calibration and validation of a lumped SOFC model.

2) Steady-state characterization analysis of the SOFC system on the lumped model, and determination of optimal operation points.

3) Local stability and step response analysis of the SOFC system based on the model.

4) Frequency response and coupling analysis of the SOFC system.

The remainder of this paper is organized as follows: Section 2 briefly describes the proposed model for the SOFC system. Section 3 presents model-based analysis methods and analytical results for SOFC model. In Section 4 and Section 5, the linearization of SOFC model, frequency response and comparative results are discussed. Finally, some conclusions are provided in Section 6.

\section{Model Description of SOFC}

This section introduces the model of an open-cathode planar SOFC system. The model will be calibrated and validated using experimental data coming from a real SOFC test bench. This experimental setup is installed in the fuel cell laboratory of the Institut de Recerca en Energia de Catalunya (IREC) and it is shown in Figure 1. Specifically, the SOFC stack is installed within a climatic chamber, which is used to preheat SOFC stack, regulate stack temperature, and avoid heat emission to outside environment. Moreover, the compressed air mainly contained oxygen and nitrogen is fed into cathode channel of SOFC through an inlet manifold. This inlet manifold is placed inside of the climate chamber which can be considered as the air preheating area. Besides, oxygen in the air passes through the cathode to anode layer reacted with hydrogen. The unreacted gasses in the cathode channel will be exhausted through the outlet manifold. In the anode channel, pure hydrogen is provided by a hydrogen tank. The produced water vapor stores in the outside vessel and the unreacted hydrogen releases to atmosphere. Finally, there are two valves connected to the hydrogen tank and compressor that are used to regulate flow rates of input gases. A detailed schematic diagram of this SOFC is depicted in Figure 2. In this paper, the inlet manifold, outlet manifold and SOFC stack are considered in this model.

The lumped model of a SOFC is developed based on the following assumptions:

Assumption 1. The gases are ideal.

Assumption 2. The length of manifolds and channels is much smaller than the volume. The pressure ratio between the interior and exterior of manifolds is large enough to consider that orifice is choked [9]. 

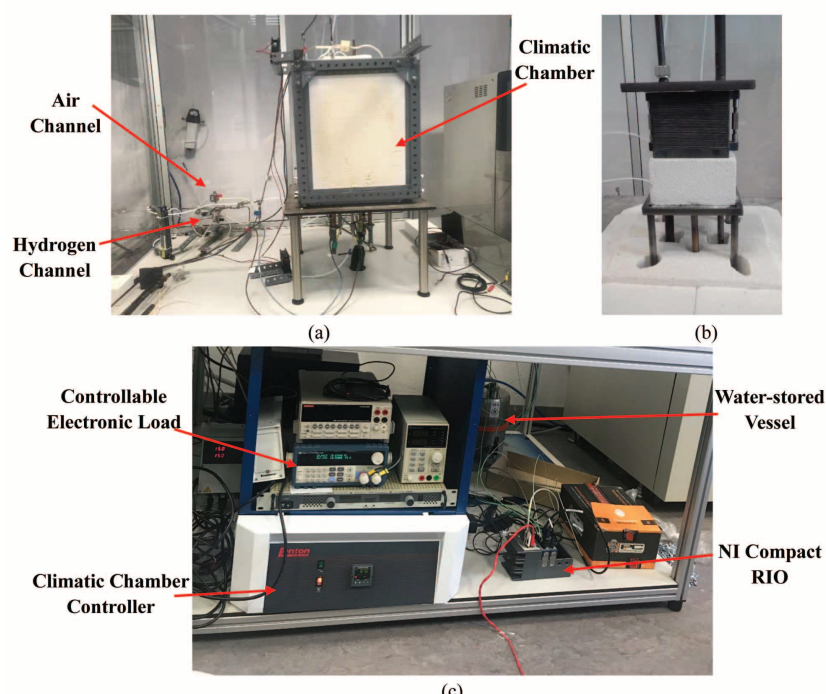

(c)

Figure 1: Laboratory test rig ((a) View of the SOFC in the test rig system; (b) SOFC stack; (c) View of controllers).

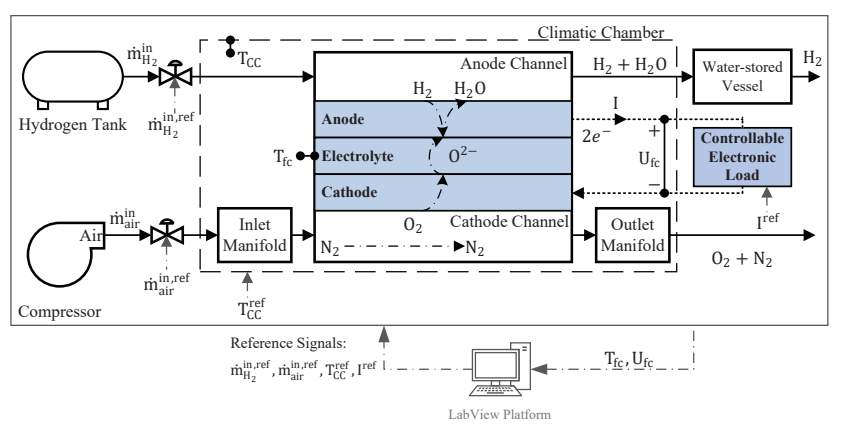

Figure 2: Schematic diagram of a SOFC system. ref in the output of the central controller (Labview platform) which are used as reference for the local controllers. When local controllers are operating appropriately, the physical values will be the same as the reference signals, i.e., $I=I^{r e f}$ ).

Assumption 3. The temperature for the whole SOFC stack is uniformly distributed.

Assumption 4. The hydrogen is fully supplied and there is no fuel starvation in the SOFC stack.

In many applications, simple diatomic gases, such as hydrogen and oxygen, can be treated as ideal gases. Moreover, water in SOFC is at the form of vapor due to high operation temperature and the quantity of water vapor is small such that water vapor is also treated as an ideal gases. Finally, the influence of temperature distribution is not considered in this paper.

In the following, the equations used to describe the behavior of each of the components will be presented and justified.

\subsection{Cathode Inlet Manifold}

According to the mass conservation principle [12], the mass balance for cathode gases can be written as

$$
\begin{aligned}
& \frac{d m_{O_{2}}}{d t}=\dot{m}_{O_{2}}^{\text {in }}-\dot{m}_{O_{2}}^{\text {out }}-\dot{m}_{O_{2}}^{r}, \\
& \frac{d m_{N_{2}}}{d t}=\dot{m}_{N_{2}}^{\text {in }}-\dot{m}_{N_{2}}^{\text {out }},
\end{aligned}
$$

where $\dot{m}_{\mathrm{O}_{2}}^{\text {in }}$ and $\dot{m}_{\mathrm{N}_{2}}^{\text {in }}$ are the input mass flows of oxygen and nitrogen, respectively; $\dot{m}_{\mathrm{O}_{2}}^{r}$ is the reacted mass flow of oxygen; $\dot{m}_{O_{2}}^{\text {out }}$ and $\dot{m}_{N_{2}}^{\text {out }}$ are the output mass flows of oxygen and nitrogen, respectively.

Specifically, the input mass flows of oxygen $\dot{m}_{\mathrm{O}_{2}}^{i n}$ and nitrogen $\dot{m}_{N_{2}}^{\text {in }}$ are calculated as follows

$$
\dot{m}_{O_{2}}^{i n}=\omega_{O_{2}}^{i n} \cdot \dot{m}_{C A}^{i n}, \quad \dot{m}_{N_{2}}^{i n}=\omega_{N_{2}}^{i n} \cdot \dot{m}_{C A}^{i n}
$$

where $\omega_{\mathrm{O}_{2}}^{i n}$ and $\omega_{N_{2}}^{i n}$ denote the input mass fractions of oxygen and nitrogen, respectively. The input mass fractions of oxygen and nitrogen are written as

$$
\omega_{O_{2}}^{i n}=\frac{\chi_{O_{2}}^{i n} M_{O_{2}}}{M_{C A}^{i n}}, \omega_{N_{2}}^{i n}=\frac{\chi_{N_{2}}^{i n} M_{N_{2}}}{M_{C A}^{i n}},
$$

where $\chi_{\mathrm{O}_{2}}^{\text {in }}$ and $\chi_{N_{2}}^{i n}$ are the input molar fractions of oxygen and nitrogen, respectively; $M_{\mathrm{O}_{2}}$ and $M_{N_{2}}$ are the molar mass of oxygen and nitrogen, respectively. The average molar mass of input mixture gases in the cathode channel $M_{C A}^{\text {in }}$ can be calculated as

$$
M_{C A}^{i n}=\chi_{O_{2}}^{i n} M_{O_{2}}+\chi_{N_{2}}^{i n} M_{N_{2}} .
$$

Based on electrochemical relationships [10], the reacted mass flow of oxygen is calculated as

$$
\dot{m}_{\mathrm{O}_{2}}^{r}=I \cdot \frac{N \cdot M_{\mathrm{O}_{2}}}{4 F},
$$

where $F$ represents Faraday's constant; $N$ is the number of cells compressed in the stack; $I$ is the stack current.

Moreover, the output mass flows of oxygen and nitrogen can be expressed as

$$
\dot{m}_{O_{2}}^{\text {out }}=\omega_{O_{2}}^{\text {out }} \cdot \dot{m}_{C A}^{\text {out }}, \quad \dot{m}_{N_{2}}^{\text {out }}=\omega_{N_{2}}^{\text {out }} \cdot \dot{m}_{C A}^{\text {out }}
$$

where $\dot{m}_{C A}^{\text {out }}$ is the output mass flow of the cathode channel, which can expressed as the following linear relationship based on Assumption 2.

$$
\dot{m}_{C A}^{\text {out }}=\left(P_{C A}-P_{O M}\right) \cdot K_{C A}
$$

where $K_{C A}$ is the cathode channel constant; and $P_{O M}$ represents the outlet manifold pressure.

The output mass fraction of oxygen $\omega_{\mathrm{O}_{2}}^{\text {out }}$ and nitrogen $\omega_{N_{2}}^{\text {out }}$ can be expressed as

$$
\omega_{O_{2}}^{\text {out }}=\frac{\chi_{O_{2}}^{\text {out }} M_{O_{2}}}{M_{C A}^{\text {out }}}, \omega_{N_{2}}^{\text {out }}=\frac{\chi_{N_{2}}^{\text {out }} M_{N_{2}}}{M_{C A}^{\text {out }}},
$$


where $\chi_{\mathrm{O}_{2}}^{\text {out }}$ and $\chi_{N_{2}}^{\text {out }}$ are the output molar fractions of oxygen and nitrogen, respectively. The average molar mass of output mixture gases in the cathode channel $M_{C A}^{\text {output }}$ can be calculated as

$$
M_{C A}^{\text {out }}=\left(\chi_{O_{2}}^{\text {out }} M_{O_{2}}+\chi_{N_{2}}^{\text {out }} M_{N_{2}}\right) .
$$

During the chemical reaction, the output molar fraction and the mass fraction change. The output molar fraction of each species related to the partial pressure can be expressed as

$$
\chi_{O_{2}}^{\text {out }}=\frac{P_{O_{2}}}{P_{C A}}, \quad \chi_{N_{2}}^{\text {out }}=\frac{P_{N_{2}}}{P_{C A}},
$$

where $P_{C A}$ is the total pressure in the cathode channel, which is the sum of partial pressure of oxygen and nitrogen. $P_{O_{2}}$ and $P_{N_{2}}$ are the partial pressure of each species, which are governed by the ideal gas law. Thus, the total pressure $P_{C A}$ and the partial pressure of oxygen $P_{\mathrm{O}_{2}}$ and nitrogen $P_{N_{2}}$ in the cathode channel are expressed as

$$
\begin{aligned}
P_{C A} & =P_{O_{2}}+P_{N_{2}} \\
P_{O_{2}} & =\frac{m_{O_{2}} R}{M_{O_{2}} V_{C A}} \cdot T_{f c}, \quad P_{N_{2}}=\frac{m_{N_{2}} R}{M_{N_{2}} V_{C A}} \cdot T_{f c}
\end{aligned}
$$

where $V_{C A}$ is the cathode channel volume; $T_{f c}$ represents the temperature of fuel cell stack.

\subsection{Anode Mass Flow Balance}

The mass balance for anode gases can be written as

$$
\begin{aligned}
\frac{d m_{H_{2}}}{d t} & =\dot{m}_{H_{2}}^{\text {in }}-\dot{m}_{H_{2}}^{r}-\dot{m}_{H_{2}}^{\text {out }}, \\
\frac{d m_{\mathrm{H}_{2} \mathrm{O}}}{d t} & =\dot{m}_{\mathrm{H}_{2} \mathrm{O}}^{\text {in }}+\dot{m}_{\mathrm{H}_{2} \mathrm{O}}^{g}-\dot{m}_{\mathrm{H}_{2} \mathrm{O}}^{\text {out }},
\end{aligned}
$$

where $\dot{m}_{\mathrm{H}_{2}}^{i n}$ and $\dot{m}_{\mathrm{H}_{2} \mathrm{O}}^{i n}$ are the input mass flow of hydrogen and water vapor, respectively; $\dot{m}_{\mathrm{H}_{2}}^{r}$ represents the reacted mass flow of hydrogen; $\dot{m}_{\mathrm{H}_{2} \mathrm{O}}^{g}$ denotes the generated mass flow of water vapor during the chemical reaction; $\dot{m}_{\mathrm{H}_{2}}^{\text {out }}$ and $\dot{m}_{\mathrm{H}_{2} \mathrm{O}}^{\text {out }}$ are the output mass flow of hydrogen and water vapor, respectively.

Then, the input mass flow of each species can be expressed by:

$$
\dot{m}_{\mathrm{H}_{2}}^{i n}=\omega_{\mathrm{H}_{2}}^{i n} \cdot \dot{m}_{A N}^{i n}, \quad \dot{m}_{\mathrm{H}_{2} \mathrm{O}}^{i n}=\omega_{\mathrm{H}_{2} \mathrm{O}}^{i n} \cdot \dot{m}_{A N}^{i n}
$$

where $\dot{m}_{A N}^{i n}$ is the input mass flow of the total gases in the anode channel; $\omega_{\mathrm{H}_{2}}^{i n}$ and $\omega_{\mathrm{H}_{2} \mathrm{O}}^{i n}$ are the input mass fraction of hydrogen and water vapor, respectively; They can be calculated as

$$
\omega_{H_{2}}^{i n}=\frac{\chi_{H_{2}}^{i n} M_{H_{2}}}{M_{A N}^{i n}}, \omega_{H_{2} O}^{i n}=\frac{\chi_{H_{2} O}^{i n} M_{H_{2} O}}{M_{A N}^{i n}},
$$

where $\chi_{\mathrm{H}_{2}}^{i n}$ and $\chi_{\mathrm{H}_{2} \mathrm{O}}^{\text {in }}$ are the input molar fractions of hydrogen and water vapor, respectively; $M_{H_{2}}$ and
$M_{\mathrm{H}_{2} \mathrm{O}}$ represent molar mass of hydrogen and water vapor, respectively; The average molar mass of input mixture gases in the anode channel $M_{A N}^{i n}$ is expressed as

$$
M_{A N}^{i n}=\chi_{H_{2}}^{i n} M_{H_{2}}+\chi_{H_{2} \mathrm{O}}^{i n} M_{\mathrm{H}_{2} \mathrm{O}} .
$$

Based on the electro-chemical relationships [10], the reacted mass flow of hydrogen and the generated mass flow of water vapor can be calculated as

$$
\begin{aligned}
\dot{m}_{H_{2}}^{r} & =I \cdot \frac{N \cdot M_{H_{2}}}{2 F}, \\
\dot{m}_{H_{2} \mathrm{O}}^{g} & =I \cdot \frac{N \cdot M_{\mathrm{H}_{2} \mathrm{O}}}{2 F} .
\end{aligned}
$$

The output mass flow of hydrogen $\dot{m}_{H_{2}}^{\text {out }}$ and water vapor $\dot{m}_{\mathrm{H}_{2} \mathrm{O}}^{\text {out }}$ can be written as

$$
\dot{m}_{H_{2}}^{\text {out }}=\omega_{H_{2}}^{\text {out }} \cdot \dot{m}_{A N}^{\text {out }}, \quad \dot{m}_{H_{2} O}^{\text {out }}=\omega_{H_{2} O}^{\text {out }} \cdot \dot{m}_{A N}^{\text {out }} .
$$

where the total output mass flow rate of anode channel $\dot{m}_{A N}^{\text {out }}$ is calculated as

$$
\dot{m}_{A N}^{\text {out }}=\left(P_{A N}-P_{a t m}\right) \cdot K_{A N},
$$

where $K_{A N}$ is the anode channel constant; $P_{a t m}$ represents the atmospheric pressure.

The output mass fraction of hydrogen $\omega_{\mathrm{H}_{2}}^{\text {out }}$ and water vapor $\omega_{\mathrm{H}_{2} \mathrm{O}}^{\text {out }}$ are represented as

$$
\omega_{H_{2}}^{\text {out }}=\frac{\chi_{H_{2}}^{\text {out }} M_{H_{2}}}{M_{A N}^{\text {out }}}, \omega_{H_{2} \mathrm{O}}^{\text {out }}=\frac{\chi_{H_{2} \mathrm{O}^{\text {out }} M_{\mathrm{H}_{2} \mathrm{O}}}}{M_{A N}^{\text {out }}}
$$

where $\chi_{\mathrm{H}_{2}}^{\text {out }}$ and $\chi_{\mathrm{H}_{2} \mathrm{O}}^{\text {out }}$ are the output molar fractions of hydrogen and water vapor, respectively. The average molar mass of output mixture gases in the anode channel $M_{A N}^{\text {out }}$ is expressed as

$$
M_{A N}^{\text {out }}=\chi_{\mathrm{H}_{2}}^{\text {out }} M_{\mathrm{H}_{2}}+\chi_{\mathrm{H}_{2} \mathrm{O}}^{\text {out }} M_{\mathrm{H}_{2} \mathrm{O}} .
$$

The output molar fraction of hydrogen and water vapor are calculated as follows:

$$
\chi_{H_{2}}^{\text {out }}=\frac{P_{H_{2}}}{P_{A N}}, \quad \chi_{H_{2} O}^{\text {out }}=\frac{P_{H_{2} O}}{P_{A N}},
$$

where $P_{A N}$ denotes the total pressure in the anode channel; $P_{\mathrm{H}_{2}}$ and $P_{\mathrm{H}_{2} \mathrm{O}}$ are the partial pressure of hydrogen and water vapor in the anode channel. They are expressed as follows

$$
\begin{aligned}
P_{A N} & =P_{\mathrm{H}_{2}}+P_{\mathrm{H}_{2} \mathrm{O}} \\
P_{\mathrm{H}_{2}} & =\frac{m_{\mathrm{H}_{2}} R}{M_{\mathrm{H}_{2}} V_{A N}} \cdot T_{f c}, \quad P_{\mathrm{H}_{2} \mathrm{O}}=\frac{m_{\mathrm{H}_{2} \mathrm{O}} R}{M_{\mathrm{H}_{2} \mathrm{O}} V_{A N}} \cdot T_{f c},
\end{aligned}
$$

where $V_{A N}$ is the anode channel volume. 


\subsection{Stack Voltage}

The SOFC output voltage can be computed as $[7,1,24]$

$$
U_{f c}=N \cdot\left(U_{n e r}-U_{a c t}^{C A}-U_{a c t}^{A N}-U_{o h m}-U_{c o n}\right),
$$

where $U_{n e r}$ represents the Nernst reversible voltage; $U_{a c t}^{C A}$ and $U_{a c t}^{A N}$ are activation losses in cathode and anode channel, respectively; $U_{o h m}$ and $U_{c o n}$ are ohmic and concentration losses, respectively.

The Nernst voltage of SOFC is a voltage change in the Gibbs free energy for electro-chemical reactions. The partial pressure of the reactants and products can affect the change of Gibbs free energy [4, 15]. Thus, the Nernst Voltage related to the partial pressure can be calculated by

$$
U_{n e r}=\Delta E_{0}+\frac{T_{f c} R}{2 F} \ln \left(\frac{P_{H_{2}} \sqrt{P_{O_{2}}}}{P_{H_{2} O}}\right),
$$

where $\Delta E_{0}$ is the standard cell potential.

Ohmic polarization losses are related to the electrical and ionic resistance in SOFC. And those resistances are produced when ions and electrons pass through electrolyte materials. Therefore, the ohmic loss can be expressed as:

$$
U_{o h m}=R_{o h m} \cdot I
$$

where $R_{o h m}$ is a cell resistance which is a function related to the fuel cell temperature. A second-order Steinhart-Hart equation is used to express cell resistance [20,12], that is

$$
\boldsymbol{R}_{\text {ohm }}=\boldsymbol{R}_{0} \cdot e^{\left[\beta\left(\frac{1}{T_{f c}}-\frac{1}{T_{0}}\right)\right]}
$$

where $R_{0}$ is specific resistance at certain temperature $T_{0} ; \beta$ represents a coefficient in the Steinhart-Hart equation.

Activation losses are the energy which reactants need to overcome in the chemical reactions, occurring at each electrode-electrolyte interface. The full butler-Volmer (B-V) equation is used to express the activation losses. However, it is difficult to solve this equation implicitly. Due to this, a hyperbolic sine function is used to approximate $\mathrm{B}-\mathrm{V}$ equation[13], which is expresses as follows

$$
\begin{aligned}
U_{a c t}^{C A} & =\frac{T_{f c} R}{2 \alpha^{C A} F} \sinh ^{-1}\left(\frac{I}{2 A_{f c} i_{0}^{C A}}\right) \\
U_{a c t}^{A N} & =\frac{T_{f c} R}{2 \alpha^{A N} F} \sinh ^{-1}\left(\frac{i}{2 A_{f c} i_{0}^{A N}}\right) .
\end{aligned}
$$

where $\alpha^{C A}$ and $\alpha^{A N}$ denote the charge transfer coefficient for cathode and anode, respectively. The exchange current densities for cathode $i_{0}^{C A}$ and anode $i_{0}^{A N}$ are calculated by Arrhenius law [4].

$$
\begin{aligned}
i_{0}^{C A} & =\gamma_{C A}\left(\frac{P_{\mathrm{O}_{2}}}{P_{r e f}}\right) e^{0.25}\left(-\frac{E_{a c t}^{C A}}{T_{f c} \cdot R}\right) \\
i_{0}^{A N} & =\gamma_{A N}\left(\frac{P_{H_{2}}}{P_{\text {ref }}}\right)\left(\frac{P_{H_{2} O}}{P_{r e f}}\right) e^{\left(-\frac{E_{a c t}^{A N}}{T_{f c} \cdot R}\right)}
\end{aligned}
$$

where $\gamma_{C A}$ and $\gamma_{A N}$ are pre-exponential factors for cathode and anode channel in Arrhenius law, respectively; $P_{r e f}$ is reference partial pressure, $E_{a c t}^{C A}$ and $E_{a c t}^{A N}$ are activation energy for cathode and anode channel, respectively.

The concentration loss accounts for the potential loss because of the diffusion of reactants and products between the bulk flow and the reaction site [9]. The concentration loss is calculated as

$$
U_{c o n}=\frac{T_{f c} R}{2 F} \ln \left(1-\frac{I}{I_{L}}\right)
$$

where $I_{L}$ is the limiting current.

\subsection{Thermal Energy Balance}

According to Assumption 3, the electrolyte structure and the gases inside channels have the same temperature. There is no temperature variation happened in the electrolyte layer and gases channels. Regarding to the SOFC stack operation process, the thermal energy consists of the input gas enthalpy, output gas enthalpy, reaction enthalpy, electrical power, heat convection[9, 12]. Thus, the thermal energy balance is expressed as

$$
\begin{aligned}
& \frac{d T_{f c}}{d t}=\frac{1}{m_{f c} C_{p}^{f c}}\left[\sum_{C A} \frac{\dot{m}_{i}^{i n}}{M_{i}} \int_{T_{r e f}}^{T_{C A}^{i n}} C_{p}^{i}(T) d T\right. \\
& +\sum_{A N} \frac{\dot{m}_{i}^{i n}}{M_{i}} \int_{T_{r e f}}^{T_{A N}^{i n}} C_{p}^{i}(T) d T-\sum \frac{\dot{m}_{i}^{\text {out }}}{M_{i}} \int_{T_{r e f}}^{T_{f c}} C_{p}^{i}(T) d T \\
& \left.-\frac{\dot{m}_{H_{2}}^{r}}{M_{H_{2}}} \Delta \hat{H}_{r}^{o}-U_{f c} \cdot I-Q_{C C}\right]
\end{aligned}
$$

where $m_{f c}$ and $C_{p}^{f c}$ are the total mass and average specific heat capacity of the SOFC stack; $C_{p}^{i}$ is the specific heat of gases; $\hat{H}_{r}^{o}$ is the specific heat of chemical reaction; $Q_{C C}$ represents the convection heat transfer between climatic chamber and fuel cell temperature, which is expressed as

$$
Q_{C C}=h_{C C} A_{f c} \cdot\left(T_{f c}-T_{C C}\right),
$$

where $h_{C C}$ denotes the heat transfer coefficient; $T_{C C}$ represents the temperature of climatic chamber.

\subsection{Cathode Outlet Manifold}

The pressure of cathode outlet manifold is governed by the ideal gassses law:

$$
\frac{d P_{O M}}{d t}=\frac{\left(\dot{m}_{C A}^{\text {out }}-\dot{m}_{\text {air }}^{\text {out }}\right) \cdot T_{f c} \cdot R_{\text {air }}}{V_{O M}}
$$

where $V_{O M}$ is the outlet manifold volume; $\dot{m}_{\text {air }}^{\text {out }}$ denotes the output air mass flow rate from the outlet manifold, which can be written as

$$
\dot{m}_{\text {air }}^{\text {out }}=\left(P_{O M}-P_{\text {ref }}\right) \cdot K_{O M},
$$

where $K_{O M}$ is the outlet manifold constant. 
The aforementioned model can be rewritten as the following nonlinear state space model:

$$
\begin{aligned}
& \dot{\mathbf{x}}=\mathbf{f}(\mathbf{x}, \mathbf{u}) \\
& \mathbf{y}=\mathbf{h}(\mathbf{x}, \mathbf{u}),
\end{aligned}
$$

where $\mathbf{x} \in \mathbb{R}^{n \times 1}$ denotes the state vector; $\mathbf{u} \in \mathbb{R}^{m \times 1}$ represents the input; and $\mathbf{y} \in \mathbb{R}^{r \times 1}$ is the output; $\mathbf{f} \in \mathbb{R}^{n \times 1}$ and $\mathbf{h} \in \mathbb{R}^{r \times 1}$ are nonlinear function vectors containing the equations that have been previously introduced.

In this paper, the state, input and output of SOFC in (12) are defined as:

$$
\mathbf{u}=\left[\begin{array}{ll}
I & T_{C C}
\end{array}\right]^{\mathrm{T}}, \mathbf{y}=\left[\begin{array}{llll}
\dot{m}_{\text {air }}^{\text {out }} & \dot{m}_{\text {an }}^{\text {out }} & U_{f c} & T_{f c}
\end{array}\right]^{\mathrm{T}},
$$

$\mathbf{x}=\left[\begin{array}{llllllll}P_{I M} & m_{I M} & P_{O M} & m_{H_{2}} & m_{H_{2} O} & m_{N_{2}} & m_{O_{2}} & T_{f c}\end{array}\right]^{\mathrm{T}}$

The input variables $\mathbf{u}$ corresponds to the current $I$ and the temperature of climatic chamber $T_{C C}$. When the value of current $I$ is fixed, the reacted mass flows of oxygen and hydrogen can be directly obtained based on the electrochemical relationship (3) and (6). Thus, the current $I$ affects the chemical reaction and determines the required quantity of oxygen and hydrogen. Moreover, the climatic chamber temperature $T_{C C}$ is used to regulated the temperature of fuel cell by the convection (10). Besides, the voltage $U_{f c}$, stack temperature $T_{f c}$ and output mass flows of anode channel $\dot{m}_{a n}^{\text {out }}$ and outlet manifold $\dot{m}_{\text {air }}^{\text {out }}$ are chosen as output variables $\mathbf{y}$, which can be measured in the experiment. According to (1)-(2), (4), (5), (9) and (10), state variables $\mathbf{x}$ are defined as the air mass $m_{I M}$ and pressure $P_{I M}$ in the inlet manifold, mass of oxygen $m_{\mathrm{O}_{2}}$, nitrogen $m_{\mathrm{N}_{2}}$, hydrogen $m_{\mathrm{H}_{2}}$, water vapor $m_{\mathrm{H}_{2} \mathrm{O}}$, stack temperature $T_{f c}$, and pressure $P_{O M}$ in the outlet manifold.

The proposed model is a highly nonlinear dynamic system. This makes its analysis and control design difficult. Besides, it is necessary to develop a model-based analysis approach to predict the operation mechanisms since the inner phenomena cannot be always measured and observed in the experiment. Hence, the objective of this paper is to propose a model-based analysis for a nonlinear SOFC system, which can be used to validate the model and provide the possible information to improve the efficiency of the SOFC system.

\section{Model Analysis}

In this section, a model-based analysis is proposed for a SOFC system. Finding equilibrium points is first presented to obtain the polarization curve in the steady-state condition. Moreover, the comparison between the model results and experimental data are conducted to calibrate and validate the proposed model.

\subsection{Steady-state Behavior and Model Tuning}

In this section the model steady-state behavior will be analyzed. This analysis will be performed through the obtained equilibrium points, which correspond to those configurations (values of the state vector variables) where
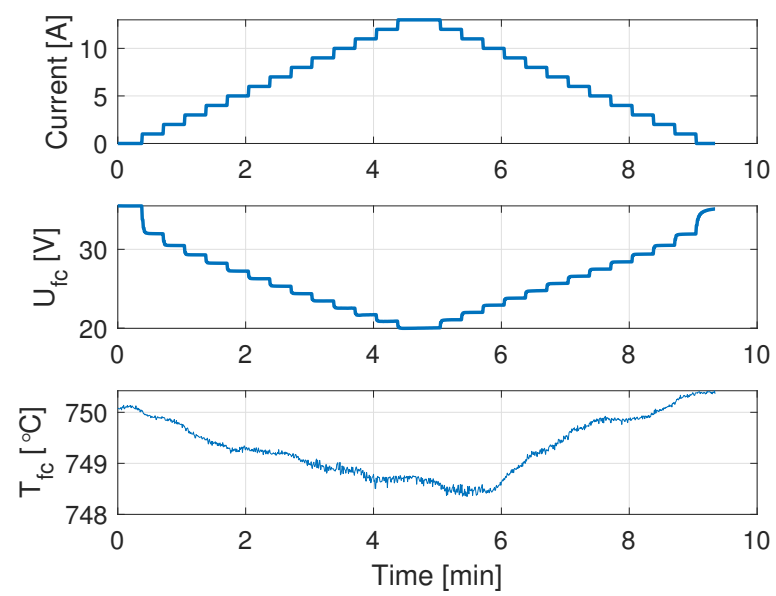

Figure 3: Experimental results obtained in the SOFC test bench. Evolution of the stack voltage $\left(U_{f c}\right)$ and temperature $\left(T_{f c}\right)$ when the current $(I)$ follows the shown profile and the climatic chamber if kept constant to $1139 \mathrm{~K}$.

the system can operate indefinitely [17]. In terms of the state-space equations, (12), equilibrium points correspond to those points which extinguish the system derivative:

$$
\begin{aligned}
\mathbf{0} & =\mathbf{f}\left(\mathbf{x}_{e q}, \mathbf{u}_{e q}, \mathbf{p}_{t}\right) \\
\mathbf{y}_{e q} & =\mathbf{h}\left(\mathbf{x}_{e q}, \mathbf{u}_{e q}, \mathbf{p}_{t}\right),
\end{aligned}
$$

where $\mathbf{x}_{e q}$ and $\mathbf{u}_{e q}$ represent the state and the input at the equilibrium points based on (13). Moreover $\mathbf{p}_{t}$ is the unknown parameters in the system model. $\mathbf{y}_{e q}$ corresponds to output variables at the equilibrium points. Note that equilibrium points are defined by (13) and $\mathbf{y}_{e q}$ is not explicitly included in (13) such that the output does not explicitly participate in the equilibrium point calculation.

Since (13) is highly nonlinear, it is difficult to analytically find the equilibrium points. Thus, (13) has been numerically solved for $\mathbf{x}_{e q}$ by fixing the value of the input $u_{e q}$ (i.e $I_{e q}$ and $T_{C C}^{e q}$ ). Once $\mathbf{x}_{e q}$ is obtained, $\mathbf{y}_{e q}$ can be easily obtained. To numerically solve (13), it is necessary to provide the numerical solver with good initial values, $\mathbf{x}_{0}$, otherwise the numerical solver might not converge. In general, it is not trivial to obtain those initial values. To manage this, an initial search mechanism has been designed to obtain an initial equilibrium point and subsequently small displacements have been made from known equilibrium points, which are allowed to generate a map of all possible existing points of equilibrium within the interested region. Besides, the equilibrium points explicitly depend on the system parameters, $\mathbf{p}_{t}$, in (13). In this work, a tuning method based on experimental data has been used (i.e. some experiments are performed in the real setup and latter a set of optimal parameters have been obtained such that the model output fits this experimental data).

To address this tuning procedure, an experiment has been designed. The climate chamber temperature reference, $T_{C C}$, is fixed at $1139 \mathrm{~K}$ which allows the fuel cell temperature to reach a fuel cell temperature close to the 


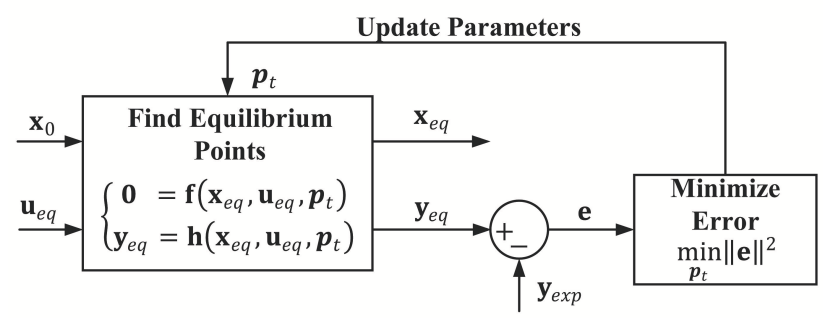

Figure 4: Flowchart of the model calibration

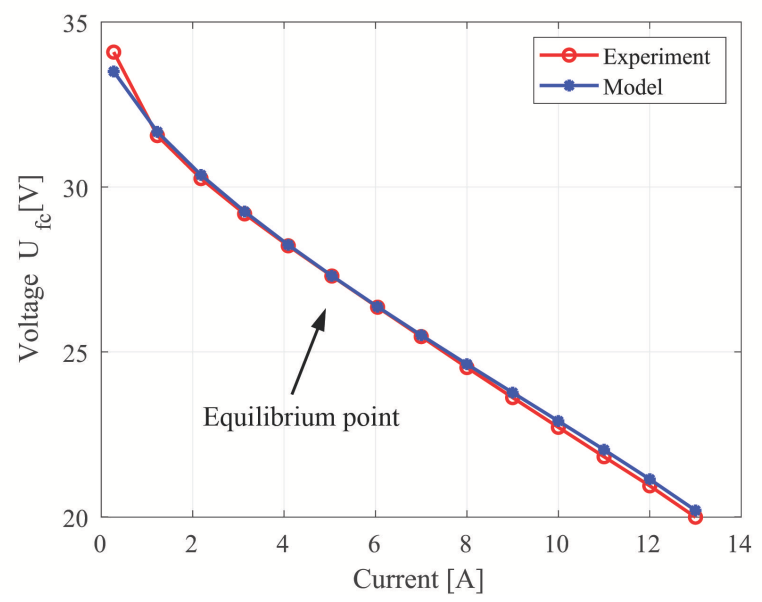

Figure 5: Comparison between the model and experimental data.

nominal operation one (around $1024 \mathrm{~K}$ ). Meanwhile, the input air mass flow and the hydrogen mass flow are set as $15 \mathrm{~L} / \mathrm{min}$ and $4.88 \mathrm{~L} / \mathrm{min}$. The current has been externally fixed to follow a given profile which can be seen in the upper graphic of Figure 3. This profile of sweeping current is from $0 \mathrm{~A}$ to $13 \mathrm{~A}$. The fuel cell voltage and temperature are simultaneously measured. The evolution of these variables can be seen in Figure 3. It is shown that the fuel cell temperature suffers variations which are less than $2^{\circ} \mathrm{C}$ over $750^{\circ} \mathrm{C}$ such that it can be considered as a constant value (these small variations can be attributed to the measurement noises and disturbances in the system). On the other hand, the voltage has an evolution which is similar to the one in the current and after a small transient it reaches the steady-state.

The tuning procedure and finding equilibrium points are performed simultaneously based on the experimental data. Figure 4 depicts the applied methodology for numerically computing a given parameter set, $\mathbf{p}_{t}$, equilibrium points $\mathbf{x}_{e q}$ and $\mathbf{y}_{e q}$. Then the error, $\mathbf{e}$, between equilibrium points obtained from the model, $\mathbf{y}_{e q}$, with ones achieved experimentally, $\mathbf{y}_{\text {exp }}$, is calculated. Finally, the optimization method is applied to minimize this error and obtain an optimal parameter set.

To implement this procedure, a SOFC model has been built using MATLAB/Simulink. Table 1 shows the physical parameters and coefficients assumed in the model. To compute the equilibrium points the 'findop' MATLAB

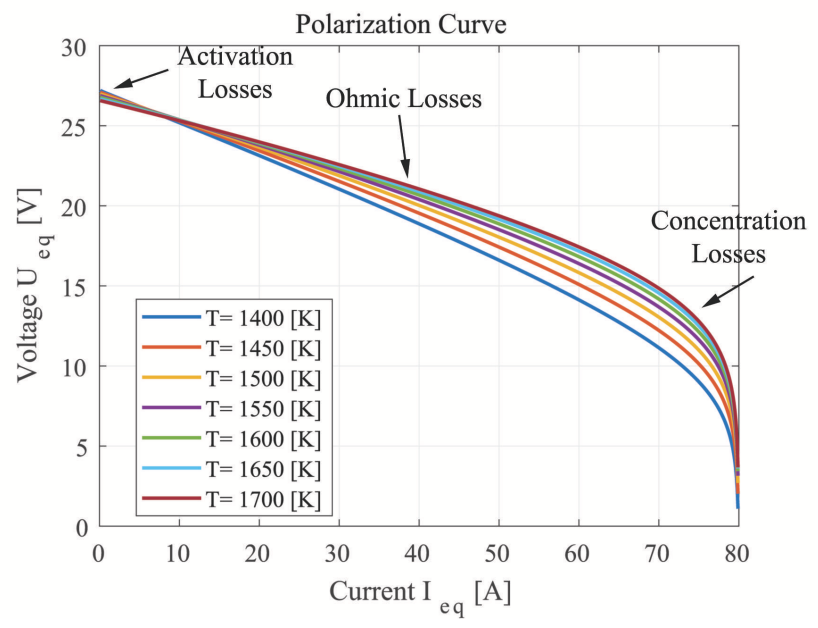

Figure 6: Model polarization curve.

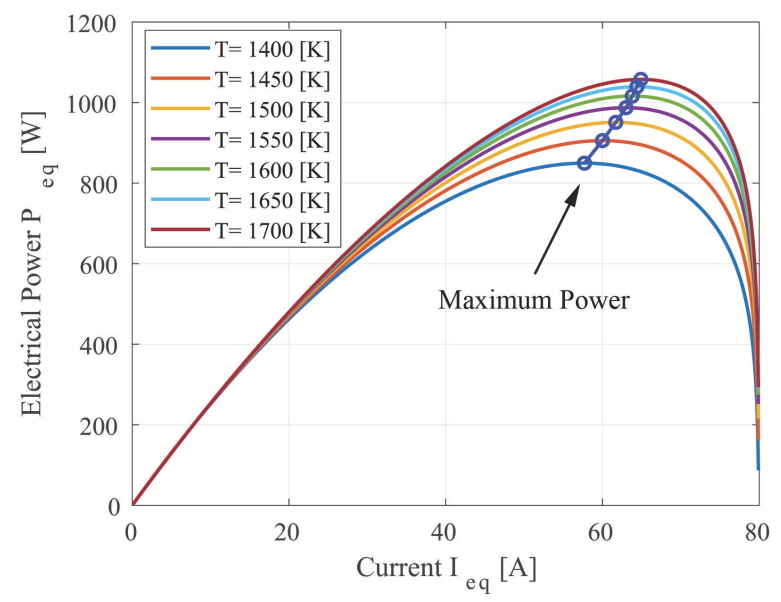

Figure 7: Electrical power versus the full cell current.

command has been used. The initial values of states $\mathbf{x}_{0}$ are shown in Table 2. Moreover, the MATLAB function 'fmincon' is used to perform the optimization and update unknown parameters. The results of tuning parameters are depicted in Table 3. In Figure 5, it is shown that equilibrium voltage points in the calibrated model match the steadystate voltage of experiment. Moreover, the proposed model shows a good fitting of the experimental data. Consequently, we assume the model is good enough to develop control systems.

\subsection{Equilibrium Points Analysis}

Based on the calibrated model, we further find equilibrium points in different temperatures and gas flow rates in order to analyze the SOFC under different operation conditions. The sweeping ranges of current and stack temperature are selected as $0.1 \mathrm{~A}$ to $80 \mathrm{~A}$ and $1400 \mathrm{~K}$ to $1700 \mathrm{~K}$, respectively. The fuel utilization is set as $60 \%$. The required input gas flow rates are directly related to current according to electro-chemical relationships (3), (6) and (7).

Figure 6 presents the relationship between the voltage 
Table 1

SOFC Model Parameters and coefficients

\begin{tabular}{|c|c|c|c|}
\hline Parameter & Value & Parameter & Value \\
\hline$A_{f c}$, SOFC stack area & $38\left[\mathrm{~cm}^{2}\right]$ & $P_{r e f}$, absolute pressure & $1.01325 \times 10^{5}[\mathrm{~Pa}]$ \\
\hline$F$, Faraday's constant & $9.6485 \times 10^{4}\left[\mathrm{C} \cdot \mathrm{mol}^{-1}\right]$ & $R$, gas constant & $8.3145\left[\mathrm{~J} \cdot \mathrm{mol}^{-1} \cdot \mathrm{K}^{-1}\right.$ \\
\hline$K_{A N}$, anode orifice constant & $1.5 \times 10^{-8}\left[\mathrm{~kg} \cdot \mathrm{Pa}^{-1} \cdot \mathrm{s}^{-1}\right]$ & $T_{A N}$, anode input gas temperature & $623[\mathrm{~K}]$ \\
\hline$K_{C A}$, cathode orifice constant & $9.385 \times 10^{-9}\left[\mathrm{~kg} \cdot \mathrm{Pa}^{-1} \cdot \mathrm{s}^{-1}\right]$ & $T_{I M}, \mathrm{IM}$ input gas temperature & $623[\mathrm{~K}]$ \\
\hline$K_{I M}$, inlet manifold orifice constant & $5 \times 10^{-8}\left[\mathrm{~kg} \cdot \mathrm{Pa}^{-1} \cdot \mathrm{s}^{-1}\right]$ & $T_{r e f}$, reference temperature & $25\left[{ }^{\circ} \mathrm{C}\right]$ \\
\hline$K_{O M}$, outlet manifold orifice constant & $3.35 \times 10^{-8}\left[\mathrm{~kg} \cdot \mathrm{Pa}^{-1} \cdot \mathrm{s}^{-1}\right]$ & $V_{I M}, \mathrm{IM}$ channel volume & $0.02\left[\mathrm{~m}^{3}\right]$ \\
\hline$m_{f c}$, SOFC stack mass & $4.3[\mathrm{~kg}]$ & $V_{O M}, \mathrm{OM}$ channel volume & $0.005\left[\mathrm{~m}^{3}\right]$ \\
\hline$M_{H_{2}}, \mathrm{H}_{2}$ molar mass & $2 \times 10^{-3}\left[\mathrm{~kg} \cdot \mathrm{mol}^{-1}\right]$ & $\alpha$, charge transfer coefficient & 0.5 \\
\hline $\mathrm{M}_{\mathrm{H}_{2} \mathrm{O}}, \mathrm{H}_{2} \mathrm{O}$ molar mass & $18 \times 10^{-3}\left[\mathrm{~kg} \cdot \mathrm{mol}^{-1}\right]$ & $\chi_{\mathrm{H}_{2}}, \mathrm{H}_{2}$ molar fraction & 0.97 \\
\hline$M_{N_{2}}, N_{2}$ molar mass & $28 \times 10^{-3}\left[\mathrm{~kg} \cdot \mathrm{mol}^{-1}\right]$ & $\chi_{\mathrm{H}_{2} \mathrm{O}}, \mathrm{H}_{2} \mathrm{O}$ molar fraction & 0.03 \\
\hline$M_{\mathrm{O}_{2}}, \mathrm{O}_{2}$ molar mass & $32 \times 10^{-3}\left[\mathrm{~kg} \cdot \mathrm{mol}^{-1}\right]$ & $\chi_{N_{2}}, \mathrm{~N}_{2}$ molar fraction & 0.79 \\
\hline$N$, number of cells & 30 & $\chi_{\mathrm{O}_{2}}, \mathrm{O}_{2}$ molar fraction & 0.21 \\
\hline$V_{A N}$, anode channel volume & $0.005\left[\mathrm{~m}^{3}\right]$ & $V_{C A}$, cathode channel volume & $0.01\left[\mathrm{~m}^{3}\right]$ \\
\hline$R_{\text {air }}$, air gas constant & $2.883 \times 10^{2}\left[\mathrm{~J} \cdot \mathrm{kg}^{-1} \cdot \mathrm{K}^{-1}\right]$ & $\Delta \hat{H}_{r}^{o}$, specific heat of reaction & $-241.83\left[\mathrm{~kJ} \cdot \mathrm{mol}^{-1}\right]$ \\
\hline $\begin{array}{l}T_{0} \text {, reference temperature for specific } \\
\text { resistance }\end{array}$ & $973[\mathrm{~K}]$ & & \\
\hline
\end{tabular}

Table 2

The initial state value

\begin{tabular}{ll}
\hline States $\mathbf{x}_{0}$ & Value \\
\hline$P_{I M}^{0}$, inlet manifold pressure & $1.49 \times 10^{5}[\mathrm{~Pa}]$ \\
$m_{I M}^{0}$, inlet manifold gas mass & $0.01089[\mathrm{~kg}]$ \\
$P_{O M}^{0}$, outlet manifold pressure & $1.1 \times 10^{5}[\mathrm{~Pa}]$ \\
$m_{\mathrm{H}_{2}}^{0}, \mathrm{H}_{2}$ mass & $1 \times 10^{-4}[\mathrm{~kg}]$ \\
$m_{\mathrm{H}_{2} \mathrm{O}}^{0}, \mathrm{H}_{2} \mathrm{O}$ mass & $4 \times 10^{-5}[\mathrm{~kg}]$ \\
$m_{\mathrm{N}_{2}}^{0}, \mathrm{~N}_{2}$ mass & $0.0037[\mathrm{~kg}]$ \\
$m_{\mathrm{O}_{2}}^{0}, \mathrm{O}_{2}$ mass & $0.00094[\mathrm{~kg}]$ \\
$T_{f c}^{0}$, stack temperature & $1015[\mathrm{~K}]$ \\
\hline
\end{tabular}

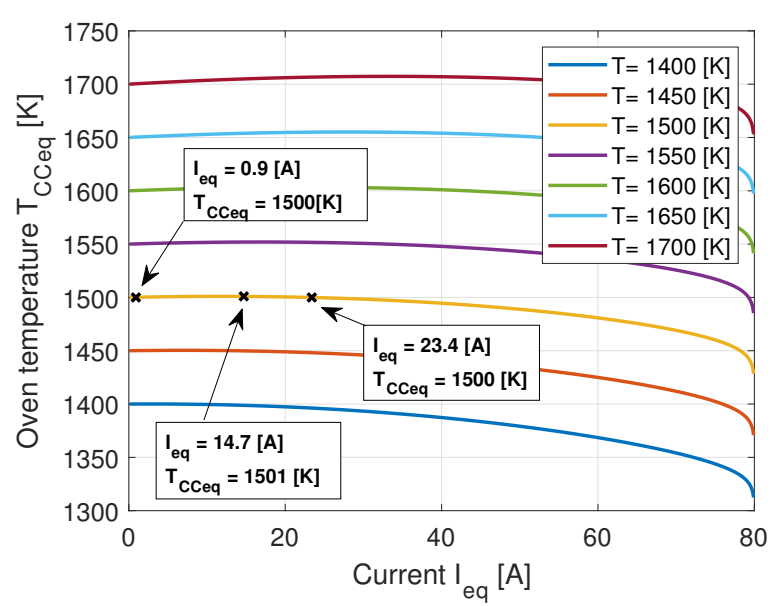

Figure 8: Curve profile between temperature of climatic chamber with current.

$U_{e q}$ and current $I_{e q}$ for different stack temperature $T_{f c, e q}$ which are usually named the SOFC polarization curve. Moreover, it is clearly seen that the region in Figure 6 where activation losses, ohmic losses and concentration losses play

\section{Table 3}

Results of Tuning Parameters to Match Experimental Data.

\begin{tabular}{ll}
\hline Parameter & Value \\
\hline$R_{0}$, area specific resistance & $0.5\left[\Omega \cdot \mathrm{cm}^{2}\right]$ \\
$E_{a c t}^{C A}$, cathode activation energy & $1.3405 \times 10^{5}\left[\mathrm{~J} \cdot \mathrm{mol}^{-1}\right]$ \\
$E_{a c t}^{A N}$, anode activation energy & $6.9002 \times 10^{4}\left[\mathrm{~J} \cdot \mathrm{mol}^{-1}\right]$ \\
$\gamma_{C A}$, cathode pre-exponential & $2 \times 10^{5}\left[\mathrm{~A} \cdot \mathrm{m}^{-2}\right]$ \\
factor in Arrhenius law & \\
$\gamma_{A N}, \quad$ anode pre-exponential & $5.8 \times 10^{5}\left[\mathrm{~A} \cdot \mathrm{m}^{-2}\right]$ \\
factor in Arrhenius law & \\
$h_{C C}$, heat transfer coefficient & $1000\left[\mathrm{~W} \cdot \mathrm{m}^{-2} \cdot \mathrm{K}^{-1}\right]$ \\
$\Delta E_{0}$, standard cell potential & $1.0047[\mathrm{~V}]$ \\
$C_{p}^{f c}$, specific heat capacity of & $10\left[\mathrm{~kJ} \cdot \mathrm{kg}{ }^{-1} \cdot \mathrm{K}^{-1}\right]$ \\
SOFC stack & \\
$T_{I M}^{i n}$, inlet manifold input gas & $950[\mathrm{~K}]$ \\
temperature & \\
$T_{A n}^{i n}, \quad$ anode input gas & $1000[\mathrm{~K}]$ \\
temperature & \\
$\beta$, Steinhart-Hart coefficient & $2 \times 10^{4}$ \\
\hline
\end{tabular}

significant impacts. Especially in the part of ohmic losses, the curve is approximately a linear line. Besides due to the limiting current $I_{L}=80 \mathrm{~A}$, the region of concentration losses have a sharp drop in Figure 6, which is very difficult to obtain in experiments.

Figure 7 shows the electrical power $P_{e q}$ against the current $I_{e q}$ for different temperatures $T_{f c, e q}$. Among those equilibrium points of electrical power, a blue curve corresponds to the maximum power for each constant temperature. This presents the trade-off between electrical power and stack temperature. Moreover, Figure 8 shows temperature changes of climatic chamber $T_{C C, e q}$ under different current $I_{e q}$ and stack temperature $T_{f c, e q}$. When stack temperature reaches to $T_{f c, e q}=1400 \mathrm{~K}$, the extra heat from climatic chamber is not required and SOFC stack can 


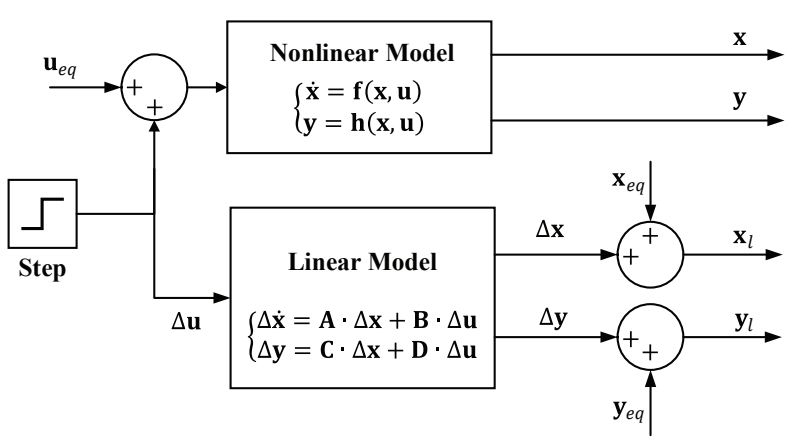

Figure 10: Flowchart of comparison of nonlinear and linear model.

maintain the temperature by its electro-chemical reaction. However, before $I_{e q}=60 \mathrm{~A}$ the climatic chamber provides a small extra heat to SOFC in order to maintain stack temperature at $T_{f c, e q}=1700 \mathrm{~K}$.

With this study it is possible to determine which is the appropriate point according to the desired characteristics (i.e. electrical power, thermal power, etc.) and the technological constrains exist in the concrete setup. After this it is straightforward to determine the references for the different control loops in a SOFC system.

\section{Stability and Time Response Analysis}

In Section 3, the SOFC's equilibrium points have been analyzed. This study only provides information about the steady-state behavior. In order to characterize the dynamic behavior, further analysis is required (i.e. trajectories around equilibrium points might be stable and unstable [17]). According to Lyapunov theory, it is possible to characterize the stability of equilibrium points and the time response for small movements around the equilibrium point using a linearized version of the original nonlinear system. In other words, when the system state $\mathbf{x}$ and the input $\mathbf{u}$ are close to the equilibrium point $\left(\mathbf{x}_{e q}, \mathbf{u}_{e q}\right)$, the system behavior can be described in terms of the following linear system.

$$
\begin{aligned}
\Delta \dot{\mathbf{x}} & =\mathbf{A} \cdot \Delta \mathbf{x}+\mathbf{B} \cdot \Delta \mathbf{u} \\
\Delta \mathbf{y} & =\mathbf{C} \cdot \Delta \mathbf{x}+\mathbf{D} \cdot \Delta \mathbf{u}
\end{aligned}
$$

where $\Delta \mathbf{x}=\mathbf{x}-\mathbf{x}_{e q} \in \mathbb{R}^{n \times 1}, \quad \Delta \mathbf{u}=\mathbf{u}-\mathbf{u}_{e q} \in \mathbb{R}^{m \times 1}$, $\Delta \mathbf{y}=\mathbf{y}-\mathbf{y}_{e q} \in \mathbb{R}^{r \times 1}, \mathbf{A}=\left.\frac{\partial \mathbf{f}}{\partial \mathbf{x}}\right|_{\mathbf{x}_{e q}, \mathbf{u}_{e q}} \in \mathbb{R}^{n \times n}, \mathbf{B}=$ $\left.\frac{\partial \mathbf{f}}{\partial \mathbf{u}}\right|_{\mathbf{x}_{e q}, \mathbf{u}_{e q}} \in \mathbb{R}^{n \times m}, \mathbf{C}=\left.\frac{\partial \mathbf{h}}{\partial \mathbf{x}}\right|_{\mathbf{x}_{e q}, \mathbf{u}_{e q}} \in \mathbb{R}^{r \times n}$ and $\mathbf{D}=$ $\left.\frac{\partial \mathbf{h}}{\partial \mathbf{u}}\right|_{\mathbf{x}_{e q}, \mathbf{u}_{e q}} \in \mathbb{R}^{r \times m}$.

According to Lyapunov's theory [17], an equilibrium point $\left(\mathbf{x}_{e q}, \mathbf{u}_{e q}\right)$ is locally asymptotically stable if all the eigenvalues of matrix $\mathbf{A}$ in (15) are placed in the left half of the complex plane. Figure 9 shows the maximum and minimum eigenvalue for matrix $\mathbf{A}$ at different equilibrium points (all the eigenvalues are real). It can be seen that all of them are negative, i.e. they are located in the left half of the complex plane. Thus, all obtained linear systems are stable, and consequently all equilibrium points from the nonlinear system are stable. Additionally, since all the eigenvalues are real no oscillations in the time response are expected.

The eigenvalues of matrix $\mathbf{A}$ also provide informations about how fast the dynamic behavior is. The maximum eigenvalue provides bounds of the settling time (how long the system can reach to the steady-state) while the minimum eigenvalue provides information about the fast modes (the bigger value the faster time response). In the studied case, the range of maximum eigenvalue is approximately from $-5.4 \times 10^{-4}$ to $-2.397 \times 10^{-3}$ (see Figure 9), and consequently the settling time would range from $1.6 \times 10^{3} \mathrm{~s}$ to $7.4 \times 10^{3} \mathrm{~s}$ depending on the concrete equilibrium point. The minimum eigenvalues are in the range from -4.6 to -3.84 which means the fastest time response is around $1 \mathrm{~s}$.

As shown in Figure 9, the evolution of the minimum eigenvalues does not change much with current and temperature whilst the maximum eigenvalues directly affect the settling time along the current. In the activation area, the maximum eigenvalues are bigger such that the settling time increases. On the contrary those values decrease as the current increase in the ohmic area. Consequently the settling constant decreases (i.e. the bigger the current is, the longer the settling time is).

Table 4

Studies Cases

\begin{tabular}{llll}
\hline Case & Polarization & Temperature & Current \\
& Loss Area & $T_{f c}[\mathrm{~K}]$ & $I[\mathrm{~A}]$ \\
\hline 1 & activation & 1500 & 0.2 \\
2 & ohmic & 1500 & 45 \\
3 & concentration & 1500 & 70 \\
\hline
\end{tabular}

As previously mentioned, when the system is around one of equilibrium points, its behavior can be described by the linear system defined in (15). Unfortunately, it is not clear how close to the equilibrium point must the system be to guarantee that the linear model is appropriate. In order to analyze this, the step response of the system will be numerically analyzed. In this analysis the scheme shown in Figure 10 is used to compare with the response of the linear system and the nonlinear one. This comparison will 

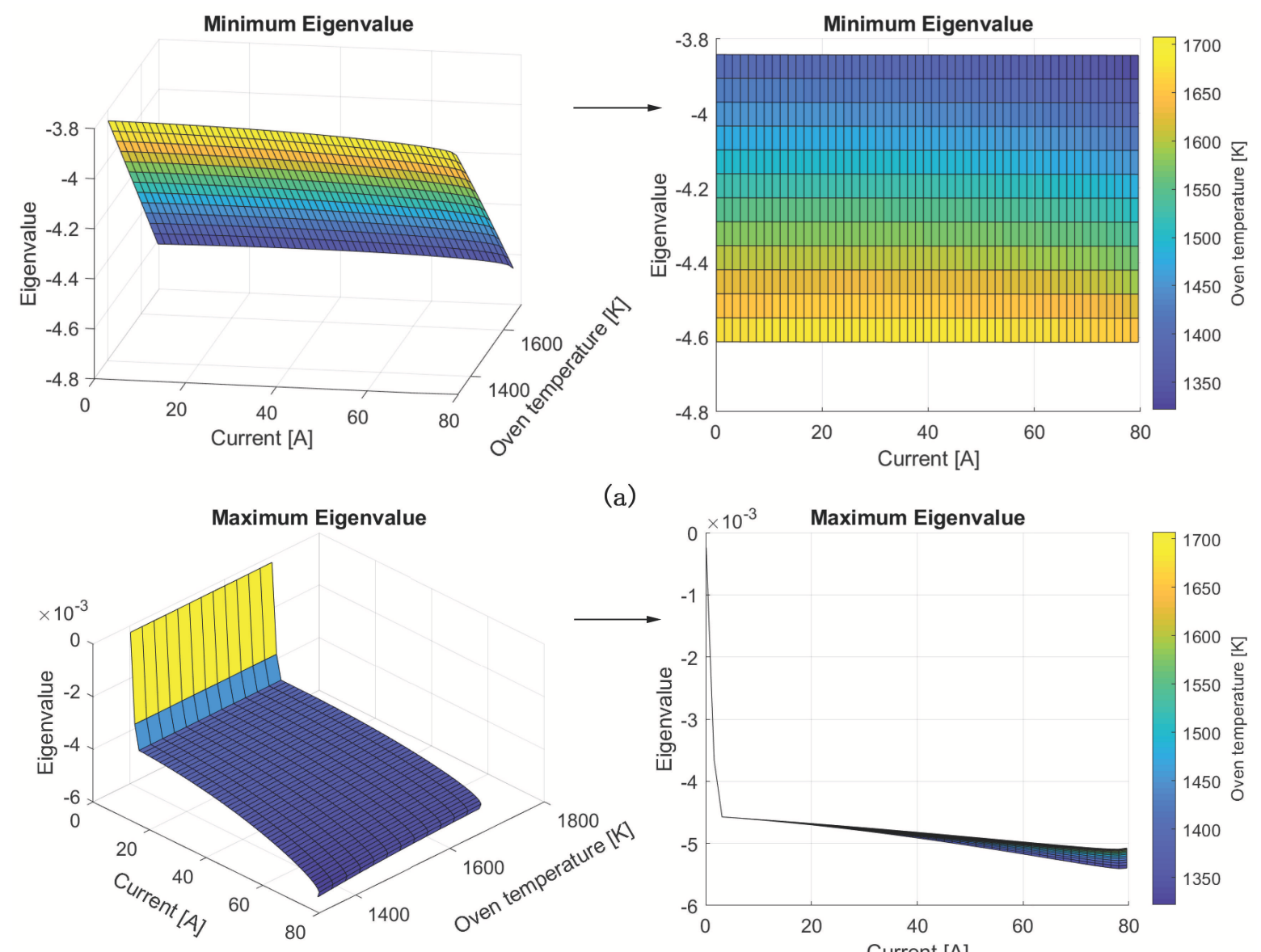

(a)

(b)

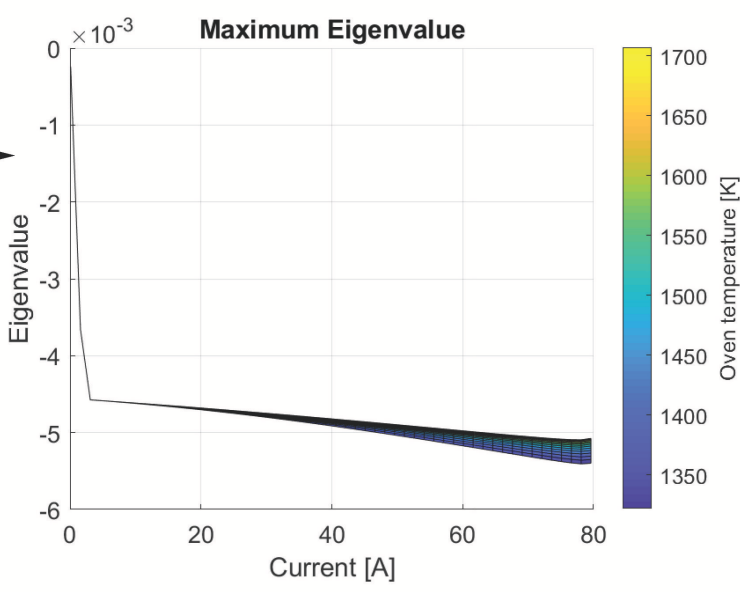

Figure 9: Eigenvalues of matrix $\mathbf{A}$ for different equilibrium points.

focus on two variables $m_{\mathrm{O}_{2}}$ and $m_{\mathrm{H}_{2} \mathrm{O}}$. Figure 11 shows the evolution of $m_{\mathrm{O}_{2}}$ and $m_{\mathrm{H}_{2} \mathrm{O}}$ when a simultaneous variation in step form is added into the input variables, $I$ and $T_{C C}$. Since the linear system depends on the equilibrium point, three different cases in different regions of the polarization curve are selected, as seen in Table 4. In each case, three different step amplitudes are used $(0.1 \%, 1 \%$ and $10 \%$ of the equilibrium point value, $I_{e q}$ and $\left.T_{C C, e q}\right)$.

Firstly, it is important to check that all the responses have a settling time in the range previously predicted through the eigenvalue analysis. Additionally, it can be observed that for almost all cases, especially in ohmic (case 2) and concentration areas (case 3), the response of the nonlinear system and the linear one are almost the same. This illustrates that the linear model would be appropriate for the tested ranges of amplitudes. In the case of activation area (case 1), although the response shape is similar, some discrepancies exist between the responses from the linear and the nonlinear systems, especially $m_{\mathrm{O}_{2}}$.

Besides, it is significant to observe that the response related to $m_{\mathrm{O}_{2}}$ shows the classical non-minimum phase behavior [16], i.e. when the step change appears the response initially goes in the opposite sense. This type of behavior introduces limitations in the control system performance and needs to be taken into account when designing control systems. Additionally, it can be seen that the response of $m_{\mathrm{H}_{2} \mathrm{O}}$ has a discontinuity at the time step which can be easily explained in terms of the system relative degree for this output.

From what have been shown in this section, it can be concluded that the range of space where the linear model is appropriate is quite reasonable (more than $10 \%$ variations can be described). Additionally, most SOFC systems operate around an equilibrium point and do not move much. Thus, understanding the performance of linear system which describes the system behavior around this equilibrium point is very helpful to design controller. Meanwhile, the controller can design directly based on those linear systems.

\section{Frequency Response Analysis}

In previous section, we focus on analyzing the time response and stability of the system behavior around equilibrium points. Although this analysis provides very important features, most powerful control techniques, such as $H_{\infty}$ [16], have been formulated in the frequency domain. In this section, the frequency response of the linearized 
Case 1:

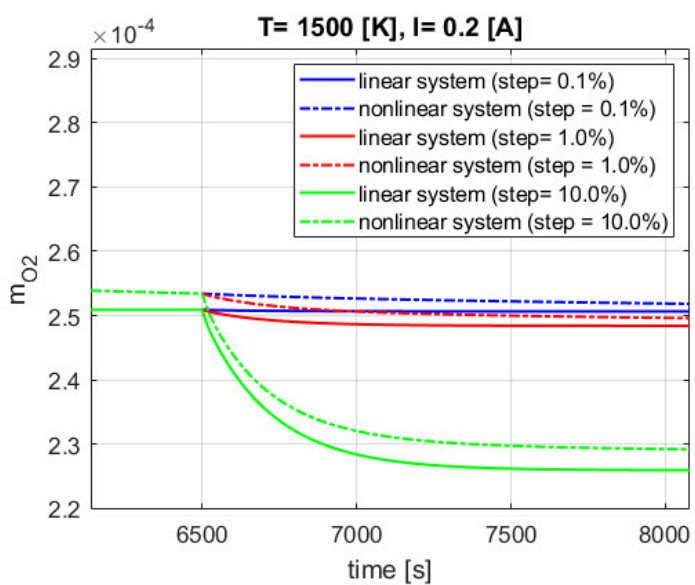

Case 2:

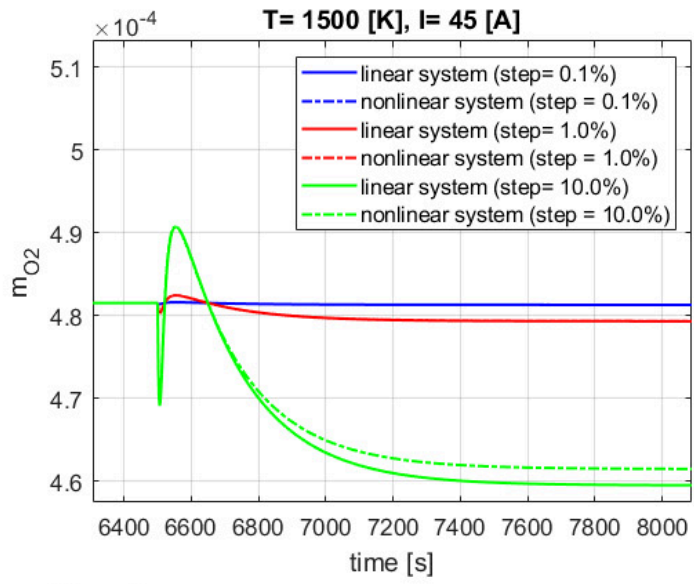

Case 3:

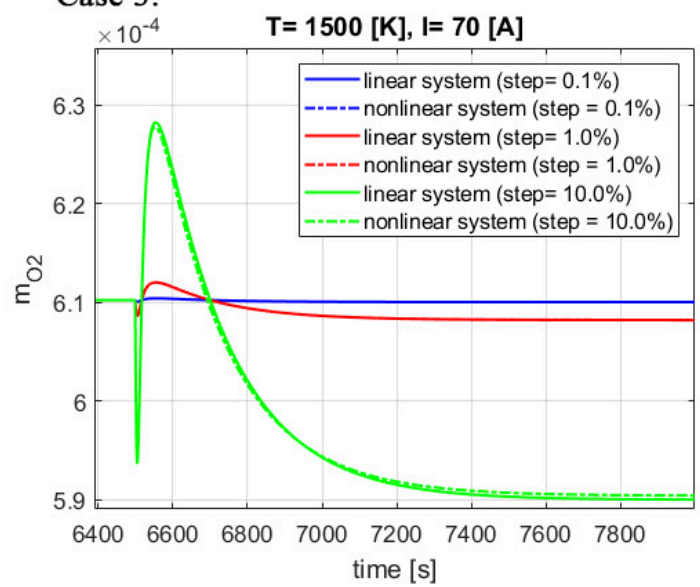

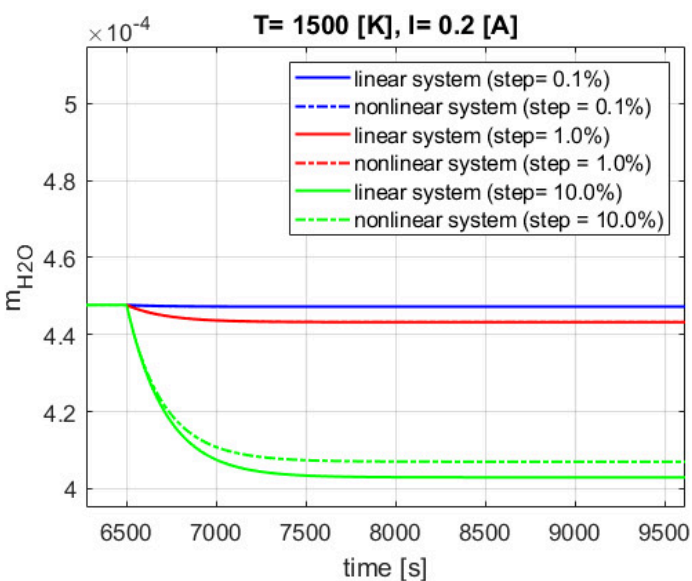
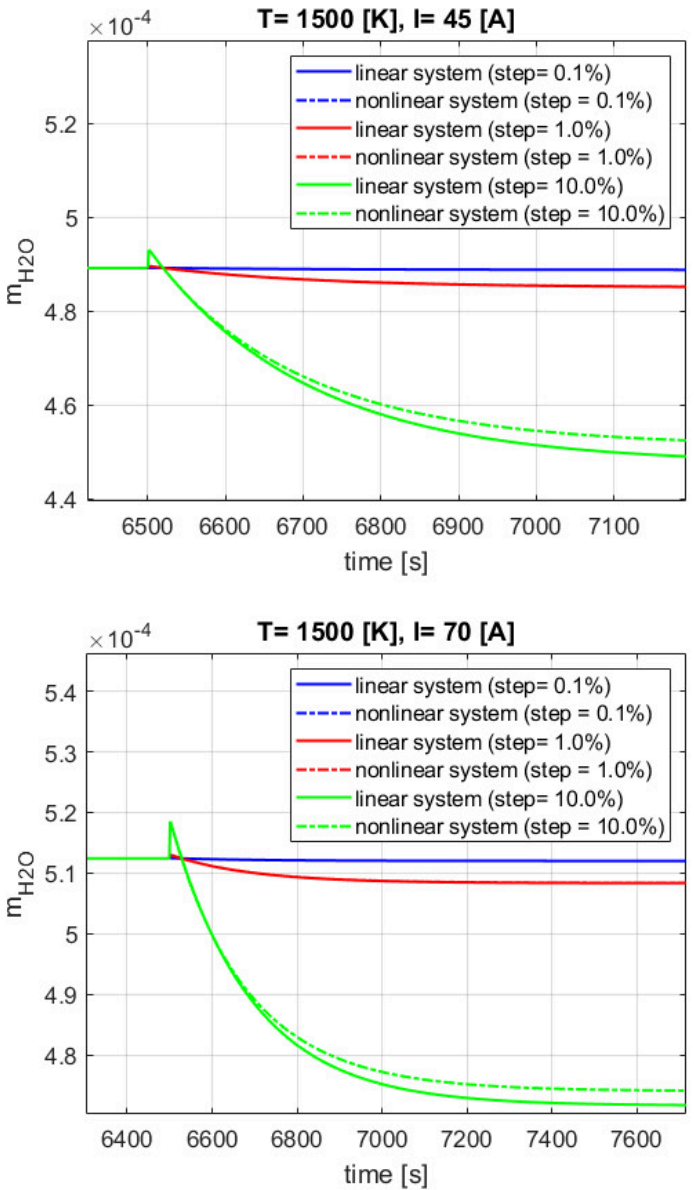

Figure 11: Comparison results between nonlinear and linear model (Case 1: activation area $T_{f c}=1500[\mathrm{~K}] I=0.2[\mathrm{~A}]$; Case 2 : ohmic area $T_{f c}=1500[\mathrm{~K}] I=45[\mathrm{~A}]$; Case 3: concentration area $\left.T_{f c}=1500[\mathrm{~K}] I=75[\mathrm{~A}]\right)$.

systems (15), will be analyzed. Frequency response characterizes how the SOFC system will respond in steadystate when sinusoidal signals of different frequencies are introduced in the inputs. Moreover, the frequency response is used to predict the system performance in closed-loop and provide the relevant information for control strategy design. Most popular frequency response representation is the Bode diagram, which shows the magnitude and phase change in the sinusoidal output respect to the input.

In this study the voltage, $U_{f c}$, and the temperature, $T_{f c}$, have been selected as output variables. They are the most relevant variables in the system and they are easy to be measured such that it is very convenient to use them for control purposes. Figure 12 shows the frequency response of the linearized SOFC model at stack temperature $T_{e q}=$ $1500 \mathrm{~K}$ and different values of current $I$. As shown in figures 


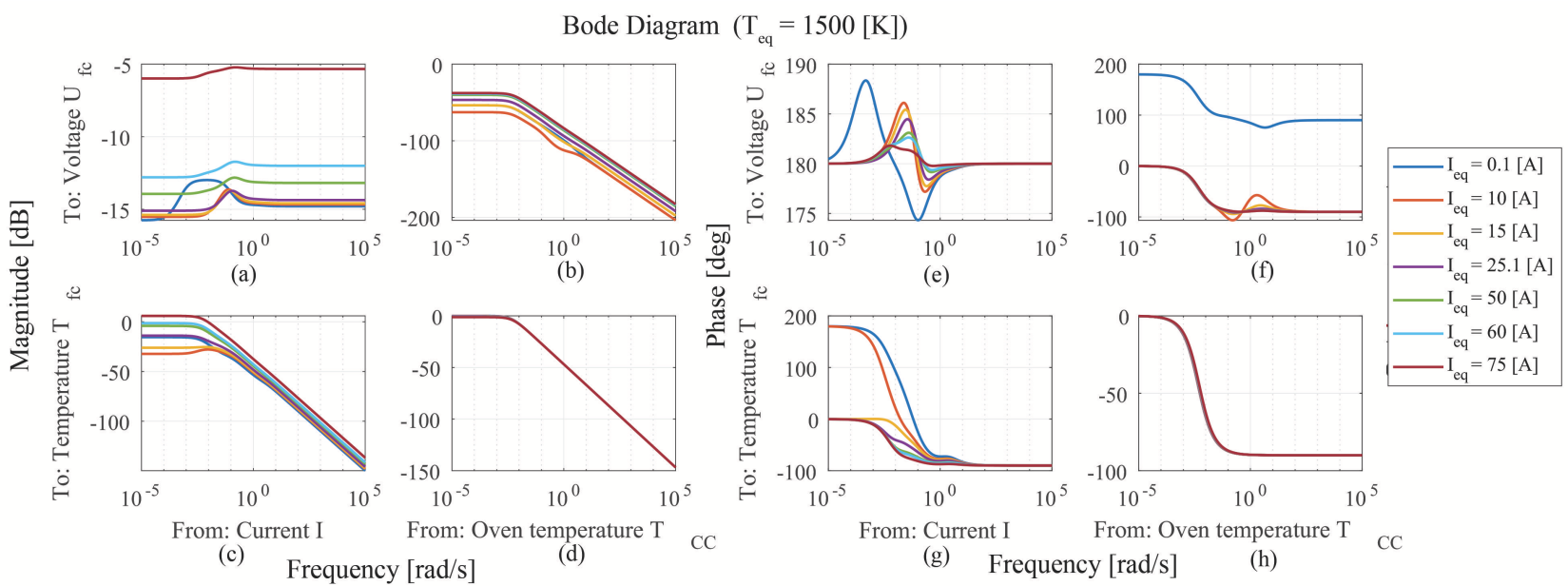

Figure 12: Frequency response for linearized system (15) for $T_{e q}=1500 \mathrm{~K}$ and different values of $I$.

12-(b), 12-(c) and 12-(d), the frequency response shows a low-pass filter profile with a band which is consistent with the time constant previously discussed (Section 4). Differently, the relationship between the current and the voltage, 12-(a), does not show this low-pass profile. Clearly, the voltage and current coupling will be faster and very sensitive to noise due the relevant gain in the high frequency range. Although most important relations are between voltage, $U_{f c}$, and current, $I$, and fuel cell temperature, $T_{f c}$, and oven temperature, $T_{C C}$, there exists a clear coupling between the voltage and the oven temperature, see Figure 12-(b), and the current and the fuel cell temperature, Figure 12-(c). Although the coupling between $T_{C C}$ and $U_{f c}$ is not very relevant, this is not the case for the coupling between $I$ and $T_{f c}$. This coupling will make the control system design more difficult. Moreover, different frequency responses are quantitatively different for each equilibrium point, even though they are qualitatively similar. Consequently the concrete operation would have no much influence on the control system behavior.

When we consider the control design, the phase plays a very important role, Figures 12-(e), 12-(f), 12-(g) and 12-(h) show phase Bode plots for the systems under study. The dynamic content has the same frequency range that in magnitude and the coupling between variables follows a similar pattern. It is important to emphasize that coupling terms change their initial values for some current values. The initial value is 0 (positive coupling) while for others it is $-180^{\circ}$ (negative coupling). This indicates that the complexity of the control system will be increased because those changes must be taken into account.

Additionally, it can be stated that the stack cannot provide enough heat to support SOFC maintaining the preheat temperature in the range of $0.1 \mathrm{~A}$ and $10 \mathrm{~A}$. This result can also be verified by the yellow line at $1500 \mathrm{~K}$ in Figure 8. For oven temperature and voltage, Figure 12-(f) illustrates that the stack voltage decreases when temperature increases. This can be verified in Figure 6 .

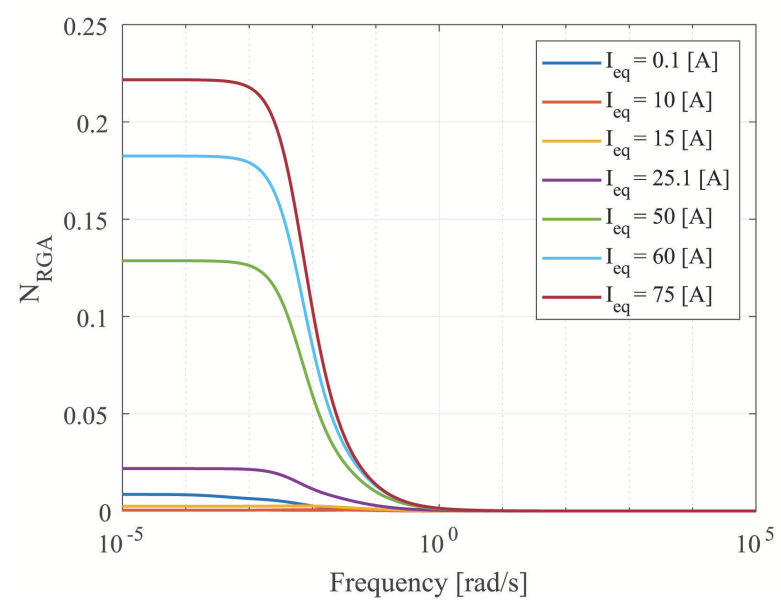

Figure 13: RGA analysis results for the linearised SOFC model.

In order to complete this analysis, the coupling between the inputs and outputs will be further quantified. The relative gain array (RGA) [16] is a mathematical tool that will help to do it. Given matrix of transfer functions, $H(s)$, the RGA is defined as: RGA $=\mathbf{H}(w \cdot j) \times\left[\mathbf{H}^{-1}(w \cdot j)\right]^{\mathrm{T}}$, where $w$ denotes the frequency. Usually, the RGA is compared with identity matrix in order to quantify the diagonal dominance in each frequency, that is

$$
N_{R G A}=\sum_{i} \sum_{j}\left\|\mathbf{R G A}_{i j}-\mathbf{I}_{i j}\right\|
$$

where I denotes identity matrix. Values close to 0 imply a perfect decoupling whilst high values illustrates that there is a strong coupling between different variables. Figure 13 shows the evolution of $N_{R G A}$ for the case under study. It can be seen that the value of $N_{R G A}$ is close to zero which means the coupling is in practice quite weak. Finally, we can draw a conclusion that a decoupled controller would provide good results. 


\section{Conclusions}

In this paper, a lumped parameter model for a SOFC system has been formulated and calibrated with data coming from experiments. Based on this model, a detailed characterization of the possible operation points has been performed. This analysis is very relevant to determine the desired operation conditions and to fix the references in the control system. Additionally, a local stability and time response analysis based on the linearized model obtained around the equilibrium points has been performed. This analysis has provided some interesting information such as the system settling time and the identification of non-minimum phase phenomena. Finally, a frequency response analysis has been performed. This analysis is used to quantify the coupling and bandwidth in the systems. Provided information about the decoupling will be of great relevance when we design control system for SOFC, i.e. using the relation of current and voltage to regulate the generated power and using oven temperature to regulate the fuel temperature. Clearly, taking into account the coupling in the control system would increase unexpected performance but also its complexity.

\section{Acknowledgments}

All authors are thankful to colleagues at the Fuel Cell Laboratory of the Institut de Recerca en Energia de Catalunya (IREC, Barcelona, Spain) who provided and assisted experimental tests.

\section{References}

[1] Barbir, F., 2005. PEM Fuel Cells: Theory and Practice. Academic Press. doi:10.1016/b978-012078142-3/50002-1.

[2] Cao, H., Li, X., 2016. Thermal Management-Oriented Multivariable Robust Control of a kW-Scale Solid Oxide Fuel Cell Stand-Alone System. IEEE Trans. Energy Convers. 31, 596-605. doi:10.1109/ TEC. 2015.2510030

[3] Casteleiro-Roca, J.L., Javier Barragan, A., Segura, F., Luis CalvoRolle, J., Manuel Andujar, J., 2019. Intelligent hybrid system for the prediction of the voltage-current characteristic curve of a hydrogenbased fuel cell. Rev. Iberoam. Automática e Informática Ind. 16, 492501.

[4] Chaisantikulwat, a., Diaz-Goano, C., Meadows, E.S., 2008. Dynamic modelling and control of planar anode-supported solid oxide fuel cell. Comput. $\{\&\}$ Chem. Eng. 32, 2365-2381. doi:10.1016/j. compchemeng. 2007.12.003.

[5] Cheng, H., Jing, S., Xu, Y., Deng, Z., Li, J., Li, X., 2016. Controloriented modeling analysis and optimization of planar solid oxide fuel cell system. Int. J. Hydrogen Energy 41, 22285-22304. doi:10.1016/ j.ijhydene.2016.08.213.

[6] Conti, B., Bosio, B., McPhail, S.J., Santoni, F., Pumiglia, D., Arato, E., 2019. A 2-D model for Intermediate Temperature Solid Oxide Fuel Cells Preliminarily Validated on Local Values. Catalysts 9, 36. doi:10.3390/catal9010036.

[7] Gebregergis, A., Pillay, P., Bhattacharyya, D., Rengaswemy, R., 2009.
Solid Oxide Fuel Cell Modeling. IEEE Trans. Ind. Electron. 56, 139148. doi:10.1109/TIE. 2008.2009516.

[8] Huo, H.B., Zhu, X.J., Cao, G.Y., 2006. Nonlinear modeling of a SOFC stack based on a least squares support vector machine. J. Power Sources 162, 1220-1225. doi:10.1016/J. JPOWSOUR. 2006.07.031.

[9] Jurado, F., 2006. A method for the identification of solid oxide fuel cells using a Hammerstein model. J. Power Sources 154, 145-152. doi:10.1016/J. JPOWSOUR. 2005.04.005.

[10] Lu, N., Li, Q., Sun, X., Khaleel, M., 2006. The modeling of a standalone solid-oxide fuel cell auxiliary power unit. J. Power Sources 161, 938-948. doi:10.1016/J. JPOWSOUR. 2006.05.009.

[11] Milewski, J., Świrski, K., 2009. Modelling the SOFC behaviours by artificial neural network. Int. J. Hydrogen Energy 34, 5546-5553. doi:10.1016/J. I JHYDENE. 2009.04.068.

[12] Murshed, A.M., Huang, B., Nandakumar, K., 2007. Control relevant modeling of planer solid oxide fuel cell system. J. Power Sources 163 , 830-845. doi:10.1016/J. JPOWSOUR. 2006.09.080.

[13] Noren, D.A., Hoffman, M.A., 2005. Clarifying the Butler-Volmer equation and related approximations for calculating activation losses in solid oxide fuel cell models. J. Power Sources 152, 175-181. doi:10.1016/j. jpowsour. 2005.03.174.

[14] Park, K., Yu, S., Bae, J., Kim, H., Ko, Y., 2010. Fast performance degradation of SOFC caused by cathode delamination in long-term testing. Int. J. Hydrogen Energy 35, 8670-8677. doi:10.1016/j. ijhydene.2010.05.005.

[15] Qi, Y., Huang, B., Chuang, K.T., 2005. Dynamic modeling of solid oxide fuel cell: The effect of diffusion and inherent impedance. J. Power Sources 150, 32-47. doi:10.1016/J. JPOWSOUR. 2005.02.080.

[16] Skogestad, S., Postlethwaite, I., 2007. Multivariable feedback control: analysis and design. volume 2. Wiley New York.

[17] Slotine, J.J.E.W.L., 1991. Applied Nonlinear Control. Prentice Hall.

[18] Sorrentino, M., Pianese, C., Guezennec, Y.G., 2008. A hierarchical modeling approach to the simulation and control of planar solid oxide fuel cells. J. Power Sources 180, 380-392. doi:10.1016/J. JPOWSOUR. 2008.02 .021$.

[19] Strahl, S., Costa-Castelló, R., 2016. Model-based analysis for the thermal management of open-cathode proton exchange membrane fuel cell systems concerning efficiency and stability. J. Process Control 47, 201-212. doi:10.1016/j. jprocont.2016.09.004.

[20] Suther, T., Fung, A.S., Koksal, M., Zabihian, F., 2011. Effects of operating and design parameters on the performance of a solid oxide fuel cell-gas turbine system. Int. J. Energy Res. 35, 616-632. doi:10.1002/er.1722.

[21] Tikiz, I., Taymaz, I., Pehlivan, H., 2019. CFD modelling and experimental validation of cell performance in a 3-D planar SOFC. Int. J. Hydrogen Energy 44, 15441-15455. doi:10.1016/J. I JHYDENE. 2019.04.152.

[22] Wang, K., Hissel, D., Péra, M.C., Steiner, N., Marra, D., Sorrentino, M., Pianese, C., Monteverde, M., Cardone, P., Saarinen, J., 2011. A Review on solid oxide fuel cell models. doi:10.1016/j . i jhydene. 2011. 03.051.

[23] Wu, X.J., Zhu, X.J., Cao, G.Y., Tu, H.Y., 2007. Modeling a SOFC stack based on GA-RBF neural networks identification. J. Power Sources 167, 145-150. doi:10.1016/J. JPOWSOUR. 2007.01.086.

[24] Xi, H., Sun, J., Tsourapas, V., 2007. A control oriented low order dynamic model for planar SOFC using minimum Gibbs free energy method. J. Power Sources 165, 253-266. doi:10.1016/J. JPOWSOUR. 2006.12.009.

[25] Yang, J., Qin, S., Zhang, W., Ding, T., Zhou, B., Li, X., Jian, L., 2017. Improving the load-following capability of a solid oxide fuel cell system through the use of time delay control. Int. J. Hydrogen Energy 42, 1221-1236. doi:10.1016/J. I JHYDENE. 2016.10.107. 